University for Business and Technology in Kosovo

UBT Knowledge Center

UBT International Conference

2013 UBT International Conference

Nov 2nd, 12:15 PM - 12:30 PM

\title{
Impact of Counterbalance Mass on Torsional Vibrations of Crankshaft
}

\author{
Asllan Hajderi \\ Aleksander Moisiu University, ashajderi@yahoo.com \\ Drakuli Lumi \\ Aleksander Moisiu University, lumidrakuli@gmail.com
}

Follow this and additional works at: https://knowledgecenter.ubt-uni.net/conference

Part of the Computer Sciences Commons, and the Engineering Commons

\section{Recommended Citation}

Hajderi, Asllan and Lumi, Drakuli, "Impact of Counterbalance Mass on Torsional Vibrations of Crankshaft" (2013). UBT International Conference. 72.

https://knowledgecenter.ubt-uni.net/conference/2013/all-events/72

This Event is brought to you for free and open access by the Publication and Journals at UBT Knowledge Center. It has been accepted for inclusion in UBT International Conference by an authorized administrator of UBT Knowledge Center. For more information, please contact knowledge.center@ubt-uni.net. 


\title{
Impact of Counterbalance Mass on Torsional Vibrations of Crankshaft
}

\author{
Asllan Hajderi ${ }^{1}$, Drakuli Lumi ${ }^{1}$ \\ 1"Aleksander Moisiu" University., Professional Studies Faculty, \\ Department of Mechanic and Transport, Durres, Albania. \\ E-mail: ashajderi@yahoo.com; lumidrakuli@gmail.com
}

\begin{abstract}
In the present study is shown how to change the main indicators of vibrations of crankshaft, in case of changing its masses. In the study it was taken the crankshaft of dies el engine with 4 cylinders in line with 5 main journals. To study the torsionalvibration of the crankshaft system, the first it is carried the construction of equivalent reduced scheme with five discs connected to four flexible shafts. Results show that the reduced inertia moments of disks for the case with counterbalances grow to $24 \%$. Free frequency and vibration forms, is calculated by using Holxer-Tole method. Results show that the increase of counterbalance mass leads in the reduction of vibration frequency. For the crankshaft with counterbalance the vibration form does not change, but the forced vibration amplitudes increase over $11 \%$. Most charge part in torsion, remains the shaft 5 equally as the crankshaft without counterbalance.
\end{abstract}

Keywor ds : crankshaft, counterbalance, frequency, vibration.

\section{Introduction}

Torsional vibration of the crankshaft are connected with the lateral system in the first set and at the end with the transmission elements of the power system. From studies results that for the crankshaft system of tractor engines, the most dangerous form of vibration is vibration forms with 4 nodes, with the first node near flywheel, which is equal to the free vibration of the crankshaft with open clutch with a node near flywheel [12]

The study was obtained crankshaft of tractor diesel engine with 4 cylinders in line produced cast iron (fig 1), which consists from 5 main journals and 8 pages, forming a crankshaft with cranks in a plan. In this crankshaft due to high loads on the main journals, occurs a large and irregular consumption of main bearings and journals, which then causes a large increase of flexible moments on pages 4,5 .

For a space $0.15 \mathrm{~mm}$ of the first main bearing and journal, which is almost the same as the consumption of middle main bearings and journals, flexible moments in 4.5 pages increase over 5 times until they cause his breaking in these pages, which is confirmed by the practice of using engines 75D [6]. To eliminate this phenomenon on the bas is of relevant dynamic study has resulted that the introduction of 4 counterbalances (each with $3.3 \mathrm{~kg}$ ), its main journals gain a greater reduction of forces acting on this (in the middle main bearings and journals have a reduction $40 \%$ of average radial load, or $13540 \mathrm{~N}$ [6]). By placing a counterbalances is achieved a monotonous consumption of main journal and bearings crankshaft, which leads to reduction of flexible moments and increasing crankshaft life

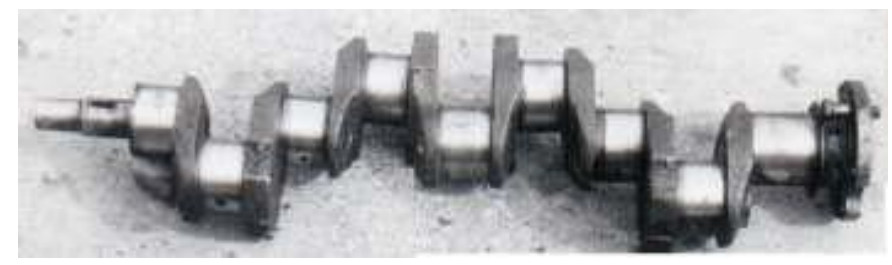

Fig. 1. The crankshaft of tractor $75 \mathrm{D}$

Setting counterbalances brings a change of rotational mass, which affects in the loading state of the crankshaft from torsional vibration. 
Vibration study of crankshaft systemis as sociated with the movement of the piston and connecting rod group. For these complexsystems, it is formed an equivalent system, which has the potential and kinetic energy equal to the real system and then are calculated the frequencies, critical speeds and resonance vibration amplitudes.

\section{Construction of the equivalent system}

Equivalent system for calculating crankshaft vibrations, or reduced scheme consists of five discs mass, connected to 4 elastic shafts without mass (Fig. 4). Construction of equivalent system consists of [10]: - Determination of reduced inertia moments of disks

- Determination of reduced rigidities of connecting elastic shaft

\subsection{Reduced inertia moments of disks}

Reduced inertia moment of a disc will be calculated:

Where:

$$
I d=I c+\operatorname{Irp}
$$

$\mathrm{Jc}$ - is the inertia moment of the crank, which for a given is determined experimentally $\mathrm{Jc}=0.0601 \mathrm{~kg}$ $\mathrm{m}^{2}[7]$

Jrp- is reduced inertia moment of the masses of the connecting rod and the piston group of a cylinder, which is a function of the rotation angle of the crankshaft[5]. In practice, it is used approximate formulas of the replacement with 2 mass (Frahm's formula), which amounts to $1 \%$ error. In this study, the inertia moment is taken constant, equal to the its average value for the rotation of crankshaft, which calculate $[5,10]$ :

$$
I_{r p}=\left[m_{1 r}+\frac{m_{j}}{2}\left(1+\frac{\lambda^{2}}{4}\right)\right] R^{2}
$$

Where

$m_{1 r}=m_{r} l a / l-$ rotational mass of connecting rod

$\mathrm{m}_{\mathrm{j}}$ - mass of the translation movement of connecting rod and piston, which is calculated:

$$
m_{j}=m_{p}+m_{j p}=m_{p}+m_{r} \frac{l-l_{a}}{l}
$$

$\lambda$ - the ratio of the radius of crank $R$ divided length of connecting $\operatorname{rod}\left(1=33 \mathrm{~cm}, 1_{\mathrm{a}}=24.8 \mathrm{~cm}\right)$ For crankshaft mass given in table 1 [6] we take: $I_{r p}=0.041 \mathrm{~kg} \mathrm{~m}^{2}$.

Table 1. Mass of translation and rotational movement.

\begin{tabular}{llll}
\hline The name of part & $\begin{array}{l}\text { Mass for translation } \\
\text { movement }\end{array}$ & $\begin{array}{l}\text { Mass for rotational } \\
\text { movement }\end{array}$ & $\begin{array}{l}\text { Distance from the } \\
\text { rotation axis } \\
\mathrm{R},[\mathrm{m}]\end{array}$ \\
\hline Piston & 3.86 & - & - \\
Connecting rod & 1.44 & 4.406 & 0.076 \\
Total & $\mathrm{m}_{\mathrm{j}}=5.30$ & $\mathrm{~m}_{1 \mathrm{r}}=4.406$ & 0.076 \\
\hline
\end{tabular}

As the inertia moment of the engine flywheel (Figure 2) will be calculated:

$$
I v=\left[\frac{\pi d_{1}^{4}}{32} a_{1}+\frac{\pi}{32}\left(d_{2}^{4}-d_{1}^{4}\right) b\right] \rho
$$


For the measured values $\mathrm{a}_{1}=20, \mathrm{~b}=80, \mathrm{~d}_{1}=180, \mathrm{~d}_{2}=400 \mathrm{~mm}$, we get: $\mathrm{Iv}=2.83 \mathrm{~kg} \mathrm{~m} 2$

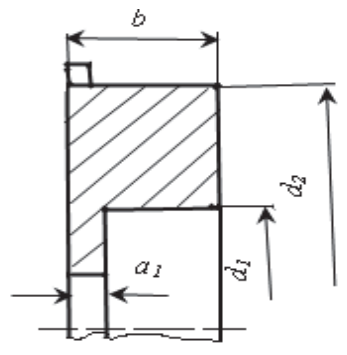

Fig 2 Schema of flywheel

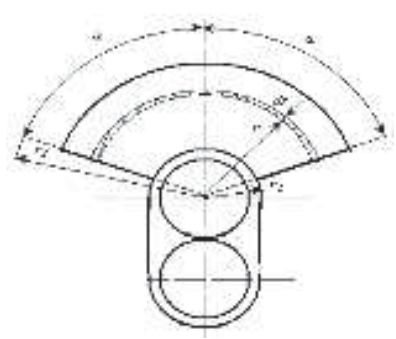

Fig. 3 Schema of counterbalance

Eventually the crankshaft without counterbalances, reduced inertia moments values of 5 discs will be:

$$
I_{1}=0.101, I_{2}=0.101, I_{3}=0.101, I_{4}=0.101, I_{5}=2.83\left[\mathrm{~kg} \mathrm{~m}^{2}\right]
$$

For crankshaft with counterbalances (located on the opposite side of pages), it will be added in the crank, inertia moment of counterbalances, which for given construction in fig. 3 calculate:

Or

$$
J_{c p}=\rho b 2 \alpha \int_{r_{1}}^{r_{2}} r^{3} d r=\rho b 2 \alpha \frac{r_{2}^{4}-r_{1}^{4}}{4}
$$

Where

$$
J_{c p}=m_{c p}\left(r_{2}^{2}+r_{1}^{2}\right) / 2
$$

$$
m_{c p}=\rho b \alpha\left(r_{2}^{2}-r_{1}^{2}\right)
$$

Where mass of counterbalance, located in every crank is different and creates add of inertia moment, $\Delta \mathrm{J}=10 \%, 20 \%, 24 \%$ and $30 \%$.

For counterbalance dimensions, width $b=30 \mathrm{~mm} \mathrm{r} 1=62 \mathrm{~mm}, \mathrm{r} 2=130 \mathrm{~mm} \quad \alpha=65^{\circ}$, we take:

$$
m_{c p}=3.3 \mathrm{~kg}, \mathrm{~J}_{\mathrm{cp}}=0.024 \mathrm{kgm}^{2}(\Delta \mathrm{J}=24 \%) \text {, }
$$

\subsection{Reduced rigidities of crank elastic shafts}

Elastic shafts are taken cylindrical shafts with diameter equal to the diameter of the main journal and the rigidities determine from the reduced length of shafts. Determination of reduced rigidities crankshaft is complex. In practice it is used semi-empirical formula, given the specialized literature [10], where estimate elasticity $(\mathrm{e}=1 / \mathrm{c})$, which depends on the constructive factors of crankshaft, such as the slope of the pages, eccentricity of the oil hole, etc..,.

Experimental measurements have shown that the rigidity of crank varies within a crankshaft, to $6 \%$ [6]. During the vibration study, we will consider the same rigidity of crank. For the given crankshaft average value of crank elasticity measured experimentally given [6]: $e=0.0628 * 10^{-6} \mathrm{rad} / \mathrm{dN} \mathrm{cm}$

Elastic shafts are reduced with the diameter of main journal and the reduced length will be calculated:

$$
l_{\text {red }}=G J p e
$$

For last shaft (5) of the crankshaft, which has length greater then other shafts $\Delta \mathrm{l}$, reduced length determined:

$$
1_{4}=1_{\text {red }} / 2+\Delta \mathrm{l}=28 / 2+11=25 \mathrm{~mm}
$$

While the rigidity determined:

$$
C_{4}=G J p / l_{4}
$$


Finally reduced rigidities of elastic shafts by cast iron GS 60-2 $\left(G=5.8 \times 10^{5} \mathrm{dN} / \mathrm{cm}^{2}\right)$, are:

$\mathrm{C}_{1}=1592356 \quad \mathrm{C}_{2}=1592356 \quad \mathrm{C}_{3}=1592356 \quad \mathrm{C}_{4}=1637330 \quad[\mathrm{Nm} / \mathrm{rad}]$

Reduced scheme to calculate the vibration crankshaft shown in Figure 4 (Values in parentheses are inertia moments for the crankshaft with counterbalance mass $3.3 \mathrm{~kg}$ )

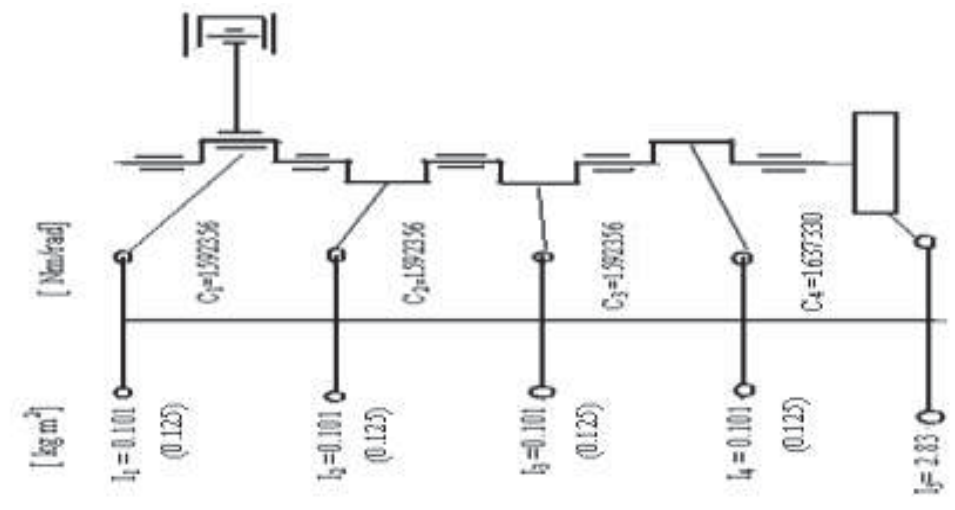

Figure 4. Reduced scheme to calculate crankshaft vibrations

\section{The frequencies and free vibration forms of crankshaft}

To determine the frequency and free vibration forms, it is used today methods without forming of differential equations of vibration. We have chosen the method Tole-Holxer [10,13 ], which is based on the principle of D'Alambert, that during the free vibration of system, the sum of moments of elasticity forces and inertia forces must be equal to zero. In this case the equations system of free vibration becomes a system algebraic equations, given [10]:

Where:

$$
\begin{gathered}
M(i)=M(i-1)+J(i) a(i) \omega^{2} \\
a(i)=a(i)-M(i) / C(i)
\end{gathered}
$$

$M(i)$ - is the moment of the elasticity forces

$a(i)$ - is the relative amplitude of free vibrations of the disc,

$\omega-$ is the frequency of free vibrations

Under this method it is formed function:

$$
R=M(n-1)+J(n) a(n) \omega^{2}
$$

Values of $\omega$, for which function $\mathrm{R}$ become to zero, are free frequencies. For this is used iterative method where the function cord interrupts the abscissa axis.

This method provides a clear statement on the substance of the made calculations, directly gives the frequency and relative amplitudes of vibration and algorithm (program) is simple.

So, frequencies and free vibration forms were calculated according to Holxer-Tole method. Below we analyzed only the two first frequencies, because they can operate in the area of engine speeds and the results of the calculations for various cases of disk inertia moments are shown in tab. 2

Table 2. Two frequencies and free vibration forms.

\begin{tabular}{llll}
\hline Inertia moment & The first free & Relative amplitudes & $\begin{array}{c}\text { The second } \\
\text { free frequency, } \\
{\left[\mathrm{kg} \mathrm{m}^{2}\right]}\end{array}$
\end{tabular}




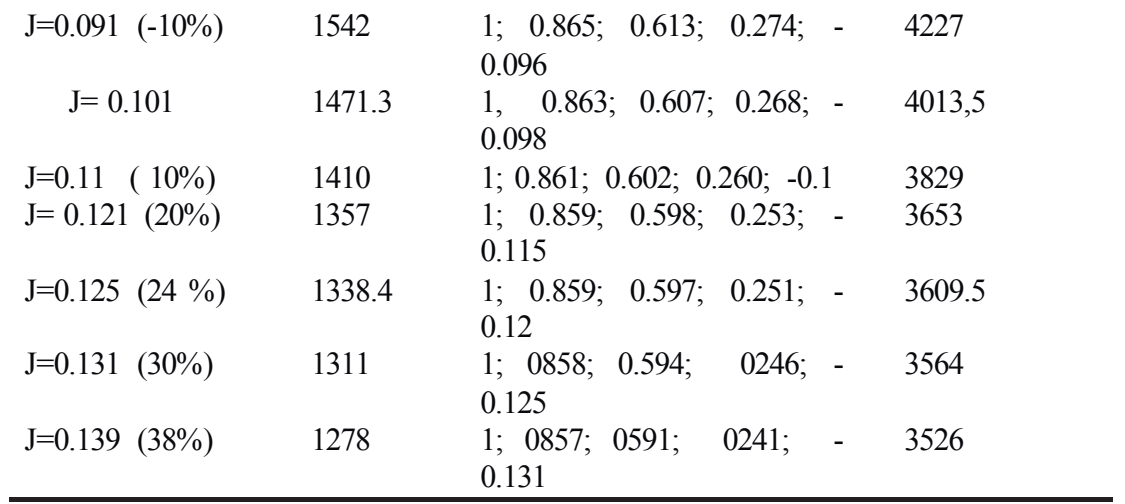

Reducing the inertia moment can be achieved by reducing the mass of the piston and connecting rod group.

The frequency changes depending on the change of inertia moments is shown in figure 5

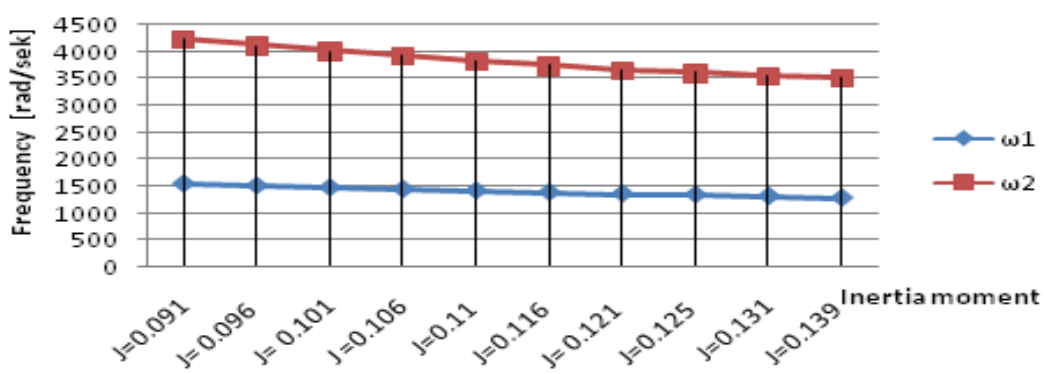

Fig. 5 Change of the vibration frequency

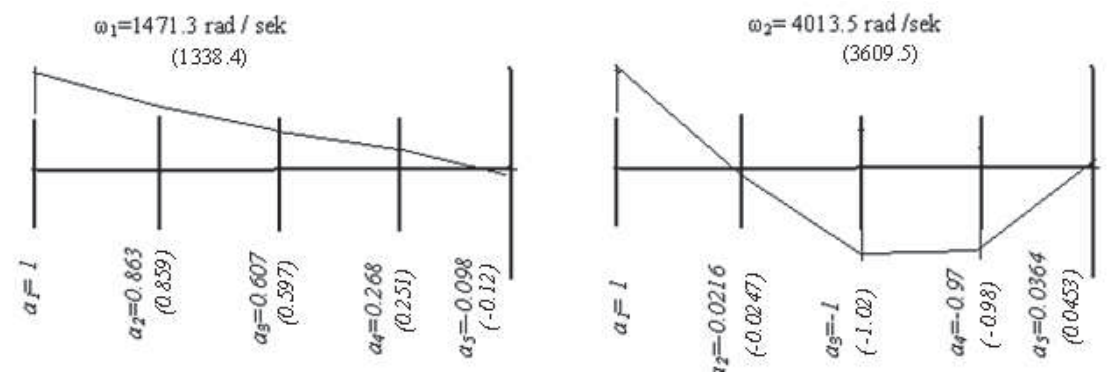

Fig. 6 Two forms of free vibration of the crankshaft system

Vibration form for the first frequencies for crankshaft with and without counterbalance are given in fig. 6 


\section{Critic speeds of engine}

The development intensity of the torsionalvibration system is determined by the quantity and character of the excitation moment. In the case of crankshaft consists of moment of inertia forces and gas pressure forces.

Harmonic analysis of inertia force by the approximation of Den Hartog [2] can be expressed in four harmonics:

$$
T_{j}=m_{j} R \omega^{2}\left(\lambda \sin \omega t / 4-\sin 2 \omega t / 2-3 \lambda \sin 3 \omega t / 4-\lambda^{2} \sin 4 \omega t / 4\right)
$$

While the inertia force moment is calculated:

$$
M j=T j R
$$

Harmonic analysis of the gas pressure forces moment is performed based on the principle of linear superposition, which means that vibrations caused by not harmonic moment can be seen as the sum of harmonic vibration caused by specific harmonic components of the excitation moment [10].

Where:

$$
M_{g}(t)=M o+\sum_{k=1}^{n} M_{g k} \sin \left(k \omega t+\alpha_{k}\right)
$$

$$
\begin{aligned}
& \text { Mo. - average torque } \\
& \mathrm{M}_{\mathrm{gk}} \text { - amplitude of order harmonic } \mathrm{k} \\
& \Omega \text { - angular speed of the crankshaft } \\
& \mathrm{k} \omega \text { - frequency of order harmonic } \mathrm{k} \\
& \alpha_{\mathrm{k}} \text { - initial phase of order harmonic } \mathrm{k}
\end{aligned}
$$

The amplitude of excitation moment depend on the indicator pressure of the engine . The average effective pressure for a speed regime of engine $n_{x}$ given [3 ], [ 8]:

$$
p_{e x}=p\left(C_{1}+C_{2} n_{x} / n-\left(n_{x} / n\right)^{2}\right)
$$

where: $\mathrm{C}_{1}=0.6, \mathrm{C}_{2}=1.4$ (for diesel engine antechamber)

Recognizing constant friction losses, pressure losses from friction calculated

$$
P_{f x}=p_{i}(1-\eta)
$$

Where $\eta=0.8$ - mechanical efficiency of the engine (for diesel engine without distention $\eta=0.7,0.82$ )

Thus the ratio of the change of gas harmonic amplitudes for different speed regimes will be given:

$$
P_{i x} / p_{i}=1+\left(C_{1}+C_{2} n_{x} / n-\left(n_{x} / n\right)^{2}-1\right)
$$

The dangerous rate of a resonance regime depends on the work carried out by the respective harmonics of the excitation moment. Performed work by order harmonic k, for a vibration calculated [10] :

Where:

$$
W=\pi M_{k} A_{k l} \sum_{1}^{n} \vec{a}_{k i}
$$

$A_{k 1}$ - the vibration amplitude of the first disc under the action of harmonic $k$

$\sum_{1}^{n} \vec{a}_{k i}$ - the vector sum of the relative amplitude of free vibration, depending on the position To assess the most dangerous harmonics in real work, it is used relative work

$$
\mathrm{w}_{\mathrm{r}}=\pi \mathrm{M}_{\mathrm{k}} \sum_{1}^{n} \vec{a}_{\mathrm{ki}}
$$

The resonance phenomenon occurs when one of the frequencies of the excitation harmonics becomes equal on frequency of free vibration. Thus resonance speeds caused by i-th frequency will be determined [10]

$n_{i, k}=n_{f} / k$

where

$$
n_{f}=30 \omega_{i} / \pi
$$

$k=0.5,1,1.5,2, . .-$ excitation harmonic order for engine with 4 time

In working speeds $n<1500 \mathrm{rpm}$, free vibration of crankshaft on first frequency $\omega_{1}=1471.3 \mathrm{rad} / \mathrm{sec}$ (1338.4), are excited by the order harmonics over 9. Second frequency $\omega_{2}$ is very high from work speeds. Excitation power falls by increasing the order of the harmonics, so it is used to 24 harmonics 
Most dangerous critical speeds are determined by the relative works of these harmonics which are given in tab. 3

Table 3. Relative works of harmonics.

\begin{tabular}{|c|c|c|c|c|c|c|c|}
\hline $\mathrm{K}$ & 9 & 9.5 & 10 & 10.5 & 11 & 11.5 & 12 \\
\hline $\mathrm{W}_{\mathrm{r}}$ & 23.99 & 32.6 & 154.73 & 30.97 & 25.4 & 28.67 & 140.37 \\
\hline
\end{tabular}

From table 3 shows that the most dangerous critical speeds are those harmonics 10 and 12 . So most dangerous critical speeds $\mathrm{n}_{10}, \mathrm{n}_{12}$ depending on the change of inertia moments are given in table 4

Table 4. Most dangerous critical speeds $\mathrm{n}_{10}, \mathrm{n}_{12}$.

\begin{tabular}{lllrrrr}
\hline$\Delta \mathrm{J}$ & $-10 \%$ & 0 & $+10 \%$ & $+20 \%$ & $+24 \%$ & $+30 \%$ \\
\hline $\mathrm{n}_{10}(\mathrm{rpm})$ & 1473 & 1405 & 1347 & 1303 & 1278 & 1253 \\
$\mathrm{n}_{12}(\mathrm{rpm})$ & 1227 & 1170 & 1127 & 1087 & 1065 & 1044 \\
\hline
\end{tabular}

\section{Vibration amplitudes}

Loading condition in torsion of the crankshaft is determined by the level of forced vibration amplitudes. The method chosen for determining the amplitude is energy method, which is used for regimes within and outside the resonance zone [13]

According to the energy method the forced vibration amplitudes in the first disc excited by order harmonic $\mathrm{k}$, is defined:

$$
A_{k l}=A_{k 0} \beta
$$

Where:

$A_{k 0}-$ is balance amplitude proposed by Ker Willson $[4,13]$, which is calculated:

$$
A_{k 0}=\frac{M_{k} \sum_{1}^{n} a_{k i}}{\omega_{i}^{2} \sum_{1}^{n} J_{i} a_{i}^{2}}
$$

$\beta$ - is the dynamic factor, which is calculated :

$$
\beta=1 /\left(1-\left(\omega_{k} / \omega_{i}\right)\right)
$$

$\omega_{k}$ - frequency of exciting harmonic of order $k\left(\omega_{k}=k \omega\right)$.

For resonance areas $\left(0.9<\mathrm{k} \omega / \omega_{\mathrm{i}}<1.1\right)$, forced vibration form is very near with free vibration. Discrepancies grow by increasing the resistance forces [13]. The resistance coefficient is taken the same for all cylinders and calculated:

where:

$$
\zeta=\zeta^{\prime} F p R^{2}
$$

$\zeta$ - specific resistance coefficient (for dies el engine given $0.04-0.05 \mathrm{dN} \mathrm{sec} / \mathrm{cm}^{3}$ ) $F p$ - the piston surface

Finally the real vibration amplitude of the first disc caused by excitement harmonic of order $\mathrm{k}$ is calculated:

$$
A^{r}{ }_{k 1}=A_{k 1} / \zeta
$$

And other amplitudes

$$
A^{r}{ }_{k i}=A_{k l} a_{i}
$$


The values of the resonance vibration amplitudes of the first disc calculated for the critical speeds caused by order harmonics 10 and 12, by changing the inertia moments of discs are given in table 5

Table 5. Resonance vibration amplitudes of the first crank.

\begin{tabular}{|c|c|c|c|c|c|c|}
\hline Change $\Delta \mathrm{J}$ & $-10 \%$ & 0 & $+10 \%$ & $+20 \%$ & $+24 \%$ & $+30 \%$ \\
\hline $\begin{array}{l}\mathrm{A}_{10,1 \times 10^{-5}} \\
\mathrm{rad})\end{array}$ & ( 369 & 390 & 405 & 425 & 434 & 444 \\
\hline $\begin{array}{l}\mathrm{A}_{12,1} \times 10^{-5} \\
\mathrm{rad})\end{array}$ & ( 314 & 337 & 354 & 374 & 384 & 395 \\
\hline
\end{tabular}

While the impact of the inertia moment on critical speeds and resonance vibration amplitudes in the first disc are shown in Fig 7

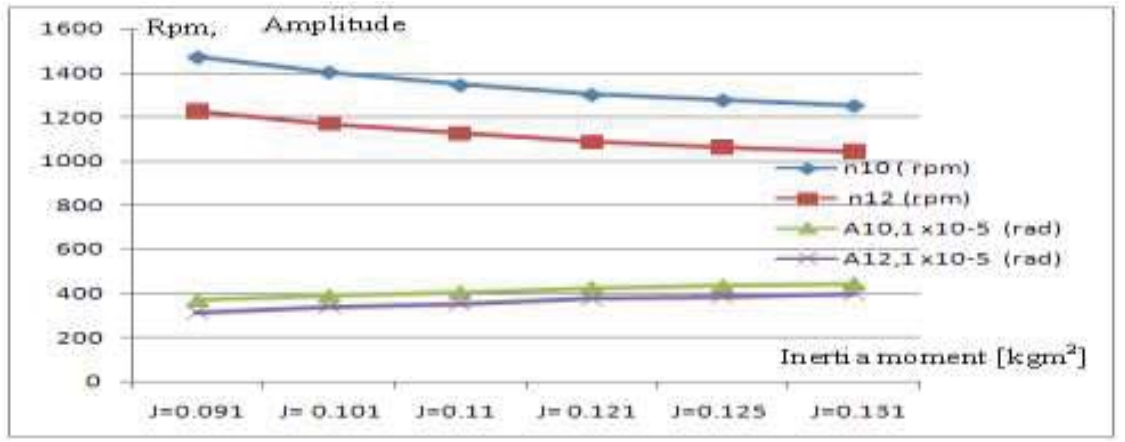

Fig. 7 Critical speeds and resonance vibration amplitudes

While the vibration amplitudes of the first crank of crankshaft without and with counterbalance $(\Delta \mathrm{J}=$ $24 \%$ ) calculated in the resonance area and outside are given in tab. 6

Table 6. Vibration amplitudes of the first crank of crankshaft.

\begin{tabular}{lllllll}
\hline $\begin{array}{c}\text { Crankshaft } \\
\text { system }\end{array}$ & without counterbalance & \multicolumn{3}{c}{ with counterbalance } \\
\hline $\mathrm{n}(\mathrm{rpm})$ & 1450 & 1405 & 1300 & 1300 & 1278 & 1200 \\
$\mathrm{~A}_{10,1} \times 10^{-5}(\mathrm{rad})$ & 0.248 & 390 & 0.108 & 0.39 & 434 & 0.13 \\
$\mathrm{n}(\mathrm{rpm})$ & 1200 & 1170 & 1100 & 1100 & 1065 & 1000 \\
$\mathrm{~A}_{12,1} \times 10^{-5}(\mathrm{rad})$ & 0.164 & 337 & 0.078 & 0.33 & 384 & 0.12 \\
\hline
\end{tabular}

\section{Discussion}

The construction of the equivalent systemfor study of cranks haft vibration has accepted approximation of the value of the inertia moment, therefore the values of frequencies and vibration amplitudes calculated will be approximate.

Holxer-Tole method is a simple method that gives accurate results in determining the frequency and relative amplitude of crankshaft vibration .

The obtained results from the calculations given in fig. 5 shows that the free vibration frequencies of crankshaft, by increasing of the inertia moments are reduced almost by linear law. While the form and relative amplitudes of vibration have very small changes. For the crankshaft with 4 counterweights frequencies are about $10 \%$ smaller than those for the crankshaft without counterbalance. 
The change of vibration relative amplitude of discs for the first frequency is small and the more charged sector remains the node to shaft 5. By placing of counterweights the change is not sensitive. The change of the relative amplitude for the second frequency is greater and the more charged sectors remain 2 nodes on shafts 1 and 4, but these are irrelevant, because the vibration with second frequency are only free. Comparing the results shows that the variant with the counterweights $(3.3 \mathrm{~kg})$, will have a increase of inertia moments of discs up to $24 \%$, which decreases the first frequency to $10 \%$.

The results given in table 5 show that the most dangerous critical speeds are those caused by the excitations of order harmonics 10 and 12 . The values of these speeds decreased with increas ing of inertia moments. For the crankshaft with counterweights $(\Delta \mathrm{J}=24 \%)$ critical speeds are reduced by $10 \%$. Increasing the inertia moment over 30\% creates the risk from the impact of the order harmonic 8 of excitation moment. The results given in table 6 and fig. 5 shows that the resonance vibration amplitudes increases by linear law, with the increase of inertia moments.

The resonance vibration amplitudes of order 12 reduced more, than those of order 10 . This shows that the dangerous by torsional vibration in critical regimes decreases with increasing the order of excitation harmonics and this confirms what is given in the literature [10 ], that for calculation enough up to 24 harmonics. Results show that for the crankshaft with counterweights resonance vibration amplitudes of the first crank increase 14\% compared with the crankshaft without counterweights.

The results given in table 7 shows that the vibration amplitudes of the crankshaft system away resonance regime are negligible compared with the resonance regimes, where the vibration amplitudes increase over 2000 times for order harmonic 10 and over 1500 times for order harmonic 12 . This shows that during study of torsional vibration of crankshaft should be calculated only vibration amplitudes in the critical speeds, corresponding to the resonance regimes. For the crankshaft with the counterweights the vibration amplitudes away resonance regime excited by order harmonic 10, increase 2 time, and excited by order harmonic 12, increase 1.4 times. While vibration amplitudes in critical speed $\mathrm{n}_{10}=$ $1278 \mathrm{rpm}$ created by order harmonic 10 increase $11 \%$, and in critical speed $\mathrm{n}_{12}=1065 \mathrm{rpm}$ created by order harmonic 12 , increase $14 \%$. So, vibration amplitude in critical speed regimes are important for solidity of the crankshafts and should be performed calculation of crankshaft vibration, if their mass change [11]

The increase of the counterweight mass that creates the inertia moment add over $30 \%$ creates the possibility of large increase of vibration amplitude, due to the introduction of smaller excitation harmonics, which are dangerous. So increasing the mass over $3.3 \mathrm{~kg}$, leads to increasing the loading state of the crankshaft and this makes, that its solidity results uncertain.

An effective intervention that reduces the dynamic tension of torsional vibration is the introduction of flexible joints in the crankshaft system, which creates the change of frequencies and free vibration forms

\section{Conclusions}

Increasing the counterweight mass placed in crankshaft, leads in the reduction of free vibration frequencies of crankshaft, while the vibration form and the relative amplitudes remain the same level. Increase of inertia moment $24 \%$ reduce the first frequency $10 \%$. Part more charged remains shaft 5 . Increasing the counterweight mass leads in reducing of engine critical speed values and can create a excitation from lower harmonics, which are more dangerous. For crankshaft with counterweight critical speeds reduce with the same rate as the first frequency.

Forced vibration amplitudes away critical speeds are not sensitive compared with those in critical speed regimes.

Vibration amplitude in critical speed regimes are important for solidity of the crankshafts. They grow with increase of inertia moments and should be performed calculation of crankshaft vibration, if their mass change. For the cranks haft with counterweight vibration amplitudes excited by the order harmonic 10 , increase $11 \%$ and those by order harmonic 12 , increase $14 \%$. 


\section{References}

1. Baljuk G. "Vibrations solidity of the engine " Moscow. (1983) 21-27 (in Russian)

2. Den Hartog, I.P. Mechanical vibrations , Paris (1960) (in French)

3. Halderman D. J. Automotive technology principles, diagnosis and service (2012)

4. Hafner K.E Torsional oscillation in the engine, Wien, New York (1985) (in German.)

5. Hafner K. E. Analysis of moving masses connecting rod-crank mechanism. Diesel gas turbine engines. Moscow (1978) ( in Russian ).

6. Hajderi, A. Influence of rotational mass and deviation from support axe in the dynamic of crankshafts disertacion, Tirane. (1991 ) 96-98 (in Albanian)

7. Hajderi, A., Hajdari V. "Case Study on Determination of Inertia Moments of Details with Complex Shapes ” International journal of basic \& applied sciences, IJBAS/IJENS, v. 12 issue 6, 28 (2012)

8. Hillier V.A.W. \& Peter Coombes Hillier's Fundamentals of Motor Vehicle Technology 5 th edition Book 1. (2005) 200, 233.

9. Kollcin, A. J. Calculation of vehicle and tractor engines, Moscow(1980) (in Russian )

10. Masllov G.S. Axes vibrations calculations, Manual date, Vehicle construction (1998) (in Russian)

11. Nazarov A. "Balancing of crankshaft during engine repair" Vehicles transport nr. 9 (1981, ) (in Russian ).

12. Popik K G. The dynamics of vehicles and tractors engine, Moscow. (1970), ( in Russian )

13. Willson, W.Ker. Practikal solution of torsional vibration problem, Volume two, Amplitude calculation ; Chapman and Hall.LTD. London (1963) 